\title{
Ética, globalização e Internet: um novo desafio*
}

José N. Heck**

\section{Resumo}

O autor discute a questão filosófico-conceitual da ética dentro do atual contexto de globalização econômica e de toda a revolução da informática. Partindo de conceitos como "universalismo" e "individualismo", o filósofo aborda o uso e o consumo das modernas redes informacionais (Internet, por exemplo) e o que isso significa do ponto de vista de comportamentos éticos.

Palavras-chave: ética; redes informacionais; globalização econômica.

\section{Introdução}

Poucas palavras têm a amplitude conceitual do termo ética. Pode-se discorrer sobre a ética enquanto disciplina filosófica, mais ou menos sofisticada, ou falar de ética como moeda corrente, ao sabor do senso comum. No primeiro caso, o conceito é subdividido em títulos como eudamonismo, hedonismo, utilitarismo, igualitarismo e assim por diante. No segundo caso, o uso da palavra evoca um elixir milagroso, receitável contra os males reais e imaginários de grupos, povos e nações. Tentarei, a seguir, equilibrar-me por entre extremos, atento ao fenômeno diferenciador da globalização econômica e do uso individual da informação dos novos tempos.

\section{Universalismo versus individualismo}

Os gregos distinguiam entre ñthos (costume), relativo à sociedade, e éthos (hábito), referente ao indivíduo. O modo como tais termos podem e/ou devem ser articulados sistematicamente

\footnotetext{
* Comunicação no IV Seminário de Biblioteconomia e Ciência da Informação no Estado de Goiás.

** Filósofo, professor titular e coordenador do mestrado em Filosofia na Universidade Federal de Goiás.
}

Comun. inf., v.1, n. 1, p. 65-73, jan./jun. 1998 
continua um assunto em aberto na discussão filosófica. Épocas prenhes de puritanismo valorizam hábitos éticos individuais, compensando a ausência de uma ética no plano social. Em contrapartida, o discurso popular sobre ética dá valor ao social por desacreditar em padrões de conduta individual. Assim, por exemplo, a era vitoriana impôs aos indivíduos o que não conseguia cobrar do império, e o populismo ético de nossos dias limita-se a exigir tudo da coletividade, deixando os indivíduos à vontade. Em suma, o puritanismo moralizante constitui uma eficiente alavanca econômica e o clamor por mais ética na política é uma prestigiosa arma dos meios de comunicação.

Sob o pano de fundo filosófico-conceitual, o universalismo de uma proposta ética postula, tendencialmente, indivíduos em ação. Desde A. Smith (1723-1790), a figura do homo oeconomicus afirma-se como agente ativo. Induzida por boicote, sua passividade pode levar o produtor de um objeto mercadológico à ruína. $O$ individualismo ético, ao contrário, tende a satisfazer seus destinatários de forma passiva. O poder de reação dos membros de uma comunidade ética apenas excepcionalmente é potencializável. Assim, provocado pelo informe de que isto ou aquilo é escandaloso, proibido, não presta ou fere os bons costumes, o indivíduo bem comportado permite-se, momentaneamente, uma febril atividade instrutiva. Dito de modo positivo: melhorar a qualidade de um produto material alimenta a expectativa de um maior número de consumidores; elevar coletivamente o nível de uma produção cultural seleciona usuários de programas educativos e justifica a existência de tevês-cultura. Essa é a razão paradoxal por que Adorno (1903-1969) fustiga a indústria cultural e se mantém complacente com os mecanismos capitalistas do mercado de bens materiais, à revelia das análises marxianas acerca do trabalho alienado. $\mathrm{Na}$ tradição do Manifesto Comunista (1848), o dinamismo universal de fatores econômicos produz efeitos desintegradores nas composições éticas tradicionais, ao passo que o universo infinito da comunicação compõe o mundo da aldeia onde, desde Aristóteles (384-322 a.C.), a opinião dominante goza de dignidade filosófica. Sob este aspecto, o drama do comunicador de massas esclarecido tem parentesco com a tra-

Comun. inf., v.1, n. 1, p. 65-73, jan./jun. 1998 
gédia do auto-eleito educador do povo. Ambos correm atrás de fatos.

Por agirem post-factum, estão normalmente atrasados.

Esta situação encontra-se atualmente em fluxo, isto é, sofre de um desarranjo concepcional. A ética não mais dá cobertura a um paradigma informacional que ameaça substituir o paradigma produtivo. Informática e Internet estão em condições de dar uma surra no capitalismo da felicidade que, tendo o consumidor por rei, dá a impressão de ser imbatível. Os novos sistemas de comunicação, a televisão digital, o WebTV, a aferição smart de audiências irão demonstrar para o velho e bom teórico do mercado com quantos paus se faz uma canoa participativa, na qual cada um é efetivamente partner de todos, colaborador intransigente dos direitos individuais, identificando a alienação no outro lado da moeda, na figura do Aufklärer, do líder instruído, do âncora ético da coletividade. Vistas a partir de tais redes informativas, em uma década nossas esclarecidas ONGs (Organizações Não-Governamentais) parecerão figuras homéricas de contestação, adolescentes precocemente envelhecidas pela conversa mole sobre o lendário congresso feminista na Cochinchina.

Em resumo, acabou o sonho de que o agente das novas tecnologias da informação seja um clone do consumidor hipnotizado por fetiches econômicos que, hoje como ontem, necessitaria ser esclarecido sobre o fato de somente a ética ter cacife suficiente para impedir que o sistema acabe em caos.

\section{Emergência e globalização}

A chamada globalização da economia constitui o último reduto de um discurso ético falido. O termo me parece um sósia desajeitado da noção reativa de imperialismo. Indício de que tal equiparação é apropriada resulta do desinteresse pelo substrato informacional da globalização, em favor do inchaço de argumentos em torno de justificações valorativas e, em consequeência, de sua recusa ou aceitação em termos culturais.

Em outras palavras, os participantes de uma discussão sobre globalização consideram-se tanto mais inteligentes quanto menos dão atenção à base operacional do fenômeno. Isso explica por que

Comun. inf., v.1, n. 1, p. 65-73, jan.jun. 1998 


\section{8}

discutir globalização é tão fascinante quanto um lero-lero gostoso sobre moda ou futebol. Há bons argumentos para quem é a favor e ótimos para quem é contra, ou seja, a globalização é um dos poucos assuntos em relação aos quais a gente pode ser otimista ou pessimista, respectivamente com boas razões. Para os primeiros, ela constitui um avanço da produção de mercado, rumo a sua planetarização, rompendo com barreiras artificiais, liquidando dinossauros aqui, oxigenando o espírito empreendedor acolá e promovendo urbi et orbi progresso, igualdade e bem-estar. Para os renitentes, a globalização não passa de um epifenômeno financeiro, o mercado artificial do dinheiro ocioso, vagabundeando por um mundo que produtivamente cresce pouco, com índices crescentes de desemprego, maniqueu, convivendo com sofisticadas tecnologias setorizadas ebolsões sempre maiores de miséria, exclusão social e desigualdades políticas.

Para um profissional treinado em dialética, como o filósofo, o instigante no exame da mundialização econômica é a mudança dos pólos argumentativos, quer dizer, argumentos relacionados à tese são, de repente, as melhores razões da antítese, de modo que a sintese não resulta, como em Hegel (1770-1831), apenas da superação de ambas, mas torna-se possivel pela involução do problema. Assim, por exemplo, os arautos otimistas de um mercado totalmente internacionalizado omitem sugerir a abolição do Estado nacional, já por seus avós considerado um entrave econômico. Pelo contrário, o rei do baralho econômico globalizado é o Estado mínimo, desde Hobbes (1588-1679) absolutista, avesso a regras de jogo às quais se devesse ater. Esta contradição na tese passa curiosamente despercebida para os pessimistas da globalização que, munidos de toda sorte de objeções, excluem da antítese o papel negativo do Estado, já por seus ancestrais criticado como desprovido de valores, o mecanismo repressivo por excelência da modernidade, um antro de corrupção pessoal, exploração econômica e demagogia política. Pelo contrário, os antitéticos da globalização preferem revidar a tese de seus antepassados - segundo a qual um estado forte não passa de um eximio instrumento de dominação de uma classe sobre outra - a contestar a deferência silenciosa de seu contraente liberal em face da figura

Comun. inf., v.1, n. 1 , p. 65-73, jan./jun. 1998 
ímpar dos Estados nacionais no cenário de uma economia globalizada.

Esta dialética entre o dito e o não dito lança alguma luz sobre as idiossincrasias terminológicas que emprestam ao tema da globalização uma aura humanista. Ambas as partes condenam o protecionismo, favorecem a negociação entre os aglomerados econômicos regionais (União Européia, Nafta, Apec, Mercosul) e vêm na democracia o melhor corretivo à oligopolização empresarial. A dimensão ética desse humanismo dialógico pode ser sumariado com o consagrado lema ecumênico dos jogos olimpicos: para os demais, faze de conta que não te interessa anhar ou perder. Para ti mesmo, porém, seja ouro o que leves para casa.

Os dias da globalização econômica, enquanto probiematização ética, estão contados. Sustentado por redes de comunicações multifacetadas, o paradigma da produção e do consumo material dará lugar ao paradigma da informação barata e abundante, não mais atrelado à produção em série de mercadorias, mas sim à disponibilização crescente de informações, ou seja, à emergência do saber a partir da interatividade e conectividade das partes em jogo.

A mão invisível do economista Smith desenvolveu uma capacidade tão incrivel de aprendizagem que está prestes a substituir o organismo ético que ainda guiava essa mão no moralista Smith. A virtualidade computacional de poder intercambiar informes econômicos de toda ordem, sem restrições geográficas e contextuaçôes sociais, foge à atuação direta do agente ético homem e só é mais controlável por softwares que agem com autonomia na coleta, seleção, padronização e personalização de informações. Por mais complexa que cada unidade de nossa espécie seja, o sistema informacional é, como um todo, mais do que a soma dos indivíduos naturais que atuam no mundo. Cotejada com a informática, o handicap da ética está no fato cultural de pré-programar um sistema complexo da ordem humana, em vez de conceber um sistema de partes de forma que da interação entre elas possa emergir a complexidade como algo não programável por um sistema de indivíduos. Atributos éticos não são diretamente acessáveis em sua complexidade cultural e tampouco estão à mão nos homens considerados individualmente, mas sobrevêm como algo inesperado nas relações que indivíduos

Comun. inf., v.l, n. 1, p. 65-73, jan./jun. 1998 
estabelecem entre si, de maneira parecida como a complexa propriedade física "molhado" não advém de uma suposta água original simples, mas resulta da interação de oxigênio e hidrogênio, substâncias gasosas que nada tem de "molhado".

A era da Internet é a hora da moral. À simulação ética falta, ao contrário, a seriedade do know-how. O interesse do indivíduo pelas leis que regem sua comunidade é estratégico, vale dizer, quanto mais ele se atém às regras do grupo tanto maior é a oportunidade de poder enganar despercebido seus semelhantes. A simulação moral é, em contrapartida, da ordem do conhecimento. Agir moralmente não significa, para Kant (17241804), estar apenas de acordo com regras de jogo, mas sim agir em reverência a elas, de modo semelhante como não faz sentido simular um acordo em matemática por razões alheias ao universo da matemática, muito embora a melhor motivação matemática não proteja o homem contra erros e enganos, inelimináveis também na mais perfeita simulação do saber. Enquanto a ética toma por referência os outros, a moral prescreve algo a quem exige. Para a moral não interessa saber para onde a carroça da humanidade e os indivíduos com ela vão, ou a que aprendizado os demais e eu com eles nos devemos submeter, mas importa exclusivamente aquilo que cabe a mim aprender, ou o que devo eu fazer. $\mathrm{O}$ resultado da simulação racional de individualidades morais não é previsível porque exclui toda simulação coletiva por parte do indivíduo. Daquilo que a ética tradicional parte - o ordenamento racional do conjunto - isto só será objetivo, para indivíduos, se emergir como complexidade das relações racionais desses indivíduos.

Em suma, a simulação moral é a única opção racional que não concebe a tapeação como um bom recurso de convivência humana. A idéia de poder tapear a si mesmo tão-somente registra subjetivamente, segundo Kant, o fato de já estar sendo passado para trás por algum dos semelhantes, ou por todos eles. $\mathrm{O}$ argumento de que a segunda alternativa é a mais convincente constitui o melhor consolo que uma pessoa tem a esperar da ética, ao submeterse a leis que outros ou o seu grupo lhe fazem, em vez de obedecer àquelas que ele mesmo pode e se deve dar.

Comun. inf., v.1, n. 1, p. 65-73, jan./jun. 1998 


\section{Perspectivas e avaliação}

Os conceitos da informática, materializados no computador como rede invisível contínua, não livram os humanos de decepções futuras. Mas o simples fato de um universo de informações, emplacado em máquinas, não ser manipulável com a experiência que os homens adquiriram historicamente, enganando uns aos outros, assinala um novo neolítico da espécie. Contra a plausibilidade de manter em vida a ilusão de cada homem ser um rei que administra o saber da humanidade, à semelhança de o soberano autocrata usar o poder sobre seus subordinados, fala o dado coniqueiro de que a quantidade de informações, postas à disposição por um sistema como a Internet, cresce a uma taxa tão impressionante que torna impossível a um indívíduo desbancar o saber disponibilizado em base de raciocínios estratégicos, tendo em vista a persecução de interesses exteriores ao sistema informacional.

Para que a velha máxima do convívio humano, "faze o que digo, mas não faças o que faço", pudesse manter sua validade como lei do conjunto, deveria ser possível qualificar culturalmente os conhecimentos materializados em redes informacionais, submetendoos aos critérios globais da orientação ética de um grupo, nação ou coletividade. O indivíduo poderia, assim, continuar jogando no time brasileiro do saber com objetivos paraguaios, americanos, alemães ou japoneses, sem dar na vista.

A alternativa não me parece viável. Se os efeitos nocivos do uso predatório do meio ambiente não conhecem fronteiras, por que supor que o fluxo da informação só possa ocorrer no seio da família, do feudo, da nação, dos estados políticos ou dos aglomerados econômicos? Não é possível aprender algo da crítica de Lênin (1870-1924) ao imperialismo, na medida em que ela foi auto-eliminada por uma política nacionalista de grandes conglomerados nacionais? A filosofia grega clássica levou radicalmente a sério, a seu modo, a dinâmica universal do saber. Suas elaborações éticas, porém, permaneceram caudatárias ao homem grego e à sua maneira de conviver da época, a ponto de pólis e cosmo serem concebidos como homólogos. Conhecemos o resultado: o mundo grego ficou entregue às traças, enquanto o seu legado filosófico

Comun. inf., v.1, n. 1, p. 65-73, jan.jun. 1998 
subsiste até os nossos dias. Já na fase atual, a Internet elimina com facilidade contextos culturais. Informações descontextuadas, distantes no espaço real e ético podem ser pescadas com a mesma rapidez que dados contextualizados e eticamente relevantes do ponto de vista do indivíduo. Mesmo se das discussões em curso - se a Internet deva ser enquadrada na imprensa falada, escrita e televisiva ou, pelo contrário, ser tratada como uma modalidade da comunicação correspondencial, telefônica ou privada - resultar uma forma de censura ou imposição restritiva, ela será tão impraticável que não merecerá a confiança dos usuários

Criar bloqueios éticos para um sistema como o da Internet segue o raciocínio segundo o qual basta ter um bom remédio para que saibamos contra qual doença ele pode ajudar. Dispor de soluções exemplares é uma coisa, outra bem diferente é diagnosticar corretamente uma situação. Quando se considera o acervo utópi$\mathrm{co}$, as maravilhosas propostas e os gênios iluminados, que desde o paraíso perdido assistem à humanidade, vem à memória a sabedoria popular "é muito cacique para pouco índio", ou seja, enquanto as panacéias se multiplicam, os problemas continuam os mesmos. Solicitado a opinar acerca dos programas comunistas para a década pós-guerra na (ex-)Alemanha Oriental, o poeta materialista Brecht (1898-1956) observou que ao Partido faltava tão-somente trocar de povo, para que tudo viesse a ser resolvido a contento.

Quem, no caso da Internet, tirar da cartola a megadroga contra a informação como poder ficará provavelmente sentado em cima do próprio veneno. Do jeito como as coisas andam, o problema desse sistema informacional não será o de poucos dominarem muitos, mas como livrar-se da informação inútil que o alimenta. Essa não é uma questão ética ou moral, mas de discernimento puro e simples ou, como Kant diria, um problema do entendimento.

\section{Conclusão}

A ética assinala uma milenar concepção cultural a favor da coesão social com base em orientações comuns, princípios ou preceitos coletivos. Mesmo se os padrões éticos forem atributos biológicos, algo assim como a decodificação racional de um instinto 
gregário, o raio de ação da ética terá sempre o caráter da solidariedade que os membros de um grupo ou de uma comunidade dispensam uns aos outros, um fenômeno observável tanto nos humanos quanto em animais.

A complexidade gerada pelas modernas redes informacionais não é de ordem ética e tampouco está limitada a uma solidariedade grupal ou comunitária. A novidade de tais complexificações tem a qualidade de nossa ignorância acerca do código analógico utilizado pelo cérebro na emergência do raciocínio, da inteligência e das simultaneidades paralelas de processamentos sem controlador central. Em suma, em ambos os casos trata-se de complexidades não determinadas por um comando único ou princípio originário, o que nos impede de afirmar peremptoriamente que esse ou aquele desenvolvimento é mais ou menos correto, melhor ou pior do que similares.

O mal-estar generalizado que a globalização, a Internet e toda a revolução da informática causam em pessoas esclarecidas tem a ver com o fato de a ética ser, na Modernidade, um dos melhores negócios que a Antigüidade nos legou, ou seja, estabelecido uma vez como os outros irão comportar-se, o indivíduo pode, calculando a reação dos demais, matar todos os coelhos com uma só cajadada de malandro. Sob um ponto de vista da moral, em contrapartida, não tem graça alguém se prescrever uma conduta a fim de ficar em condições de passar-se espertamente para trás.

Em filosofia, vale o princípio de que bom é aquilo que a gente mesmo gosta de consumir.

\section{Abstract}

The author debates the question of the philosophical concept of ethics in the context of world economy and the revolution of computer science. Begining from the ideas of "universalism" and individualism, the philosopher approaches the use and consumption of modern computer networks (internet) and what it means to ethical behavior.

Key words: ethics; computer networks; world economy.

Comun. inf., v.1, n. 1, p. 65-73, jan.jjun. 1998 